\title{
UCRL-TR-155665
}

LAWRENCE LIVERMORE NATIONAL LABORATORY

\section{FY'03 OMEGA Summary for LLE Annual Report}

Robert E. Turner

October 24, 2003 


\section{DISCLAIMER}

This document was prepared as an account of work sponsored by an agency of the United States Government. Neither the United States Government nor the University of California nor any of their employees, makes any warranty, express or implied, or assumes any legal liability or responsibility for the accuracy, completeness, or usefulness of any information, apparatus, product, or process disclosed, or represents that its use would not infringe privately owned rights. Reference herein to any specific commercial product, process, or service by trade name, trademark, manufacturer, or otherwise, does not necessarily constitute or imply its endorsement, recommendation, or favoring by the United States Government or the University of California. The views and opinions of authors expressed herein do not necessarily state or reflect those of the United States Government or the University of California, and shall not be used for advertising or product endorsement purposes.

This work was performed under the auspices of the U.S. Department of Energy by University of California Lawrence Livermore National Laboratory under contract No. W-7405-Eng-48. 
Lawrence Livermore National Laboratory (LLNL) continued, in FY 03, to be a large user of Omega, using 390 experimental shots. These are roughly broken into 2 groups: those in support of the inertial confinement fusion (ICF) program; and those in support of high energy density sciences (HEDS), which includes materials, equation of state, and physics experiments.

\section{ICF Experiments}

The ICF program had a total of 152 shots on OMEGA during FY03. These included the following.

Charge Particle Spectroscopy Implosions, done in collaboration with MIT, where charged fusion reaction produces from indirectly driven ICF implosions were measured. Initial experiments were done to ascertain the feasibility of using multiple CPS diagnostics as a measure of implosion asymmetry.

X-ray scattering experiments showed that $\mathrm{He}$ and $\mathrm{H}$-like $\mathrm{Ti}$ x-rays can be spectrally measured after scattering off near-solid density plasmas. Theoretical fits to the data are in good agreement, opening the way for using this as a diagnostic for pusher $\mathrm{pR}$ on NIF implosions.

Cocktail (mixtures of materials) hohlraum experiments were performed to attempt to measure a predicted improvement in x-ray conversion efficiency and soft x-ray albedo. Preliminary results seem to verify the latter, but not the former.

Planar Rayleigh-Taylor experiments on polyimide were performed to assess its usefulness as an ablator for ICF capsules. Data to date indicates a higher RT growth rate than calculated, even though acceleration measurements seem to match predictions.

A number of experimental techniques expected to be used on the National Ignition Facility (NIF) were tested with Omega shots. These included high magnification $\mathrm{x}$-ray imaging of imploded capsules, using target-mounted pinholes (figure 1); and development of a K-B x-ray microscope with a spectrally narrow bandpass, to look at $\mathrm{x}$-ray line emission from a backlighter through a capsule. Additional experiments, done in collaboration with the University of Nevada-Reno, looked at spatially-resolved spectroscopic measurements of pusher density using Ti dopant within the inner layer of the capsule, while using Ar x-ray emission from the fuel region to deduce temperatures and densities in that region (figures 2 and 3 ).

Laser-plasma interaction (LPI) experiments were done to explore the interaction of the laser with the large plasmas created when gas-filled hohlraums are used. 
Most of these experiments used gas-bags as the initial target, to provide a longscalelength plasma with good diagnostic accessibility. Experiments measured Raman (SRS) and Brillouin (SBS) scattering levels, and the effect of Langmuir damping; and energy exchange through SBS in crossed-beam experiments. The $4 \mathrm{w}$ probe beam was successfully used for Thomson-scattering measurements, as shown in figure 4. Additional experiments in gas-filled hohlraums looked at the effect of the gas pressure on capsule hydrodynamics, and looked for possible enhanced gold-gas mixing due to pre-roughened hohlraum walls. Still another experiment looked for evidence of early time laser light directly striking the capsule in indirect drive experiments. These results are compared to calculations in figure 5.

Several high yield, direct drive DT implosions were done in collaboration with LANL, to provide high fluxes of $14 \mathrm{MeV}$ neutrons for diagnostic development. The characteristics of a diamond PCD device in measuring neutrons is shown in figure 6 .

\section{HEDS/NWET Experiments}

The High Energy Density Science and NWET programs used 238 laser shots on Omega during FY03. Some of the experiments are briefly described below.

A substantial number of shots ("I-Drive") were devoted to developing techniques for measuring material properties when under substantial pressures, but still in the solid state. Low temperature Rayleigh Taylor experiments were performed with this experimental arrangement. [Note to editor: I need to get a figure here].

Another large grouping of shots were devoted to using Omega to prepare for NIF-early light (NEL) experiments. These included testing concepts for pointprojection backlighting using backlit pinholes as an x-ray source. An example of this work is in figure 7, showing an excellent radiographic image of a propagating shock.

Equation of state (EOS) experiments were performed in a variety of materials, by measuring the velocity of ablatively driven shocks within the material. LLNL is a major participant in an NLUF experiment which measured shock velocities through pre-compressed gases within diamond anvil pressure cells, as shown in figure 8. Shock experiments were also used to measure opacities at elevated pressures and temperatures. 
Experiments were conducted with small hohlraums, to develop sources at elevated radiation temperatures.

Rayleigh Taylor instabilities were studied in a spherically convergent geometry, using pre-imposed perturbations on spherical capsules.

Double-shell (one shell containing DD fuel within another, concentric, indirectly driven shell) targets were explored for a number of properties, including their sensitivity to high-energy photon preheat, and the timing of the fuel shockheating compared to the timing of the fuel compression.

A number of experiments were done to look at the propagation of radiation in low density materials.

Another experiment looked at the possibility of using a direct drive configuration to create a dynamic hohlraum for driving implosions. 
- Primary diagnostics were the MMIs

- Imaging via target-mounted pinhole array, producing hundreds of $\sim 11$ $\mu \mathrm{m}$-resolution, $8 \mathrm{X}$ images

- Spectral dispersion via new depthgraded $\mathrm{WB}_{4} \mathrm{C}$ multilayer mirror with $\mathrm{E} / \Delta \mathrm{E} \sim 75$

- 3 - $5 \mathrm{keV}$ spectral coverage

- Identical MMI3a and MMI3b instruments mounted on XRFC1/TIM2, XRFC3/TIM3 for near-perpendicular views

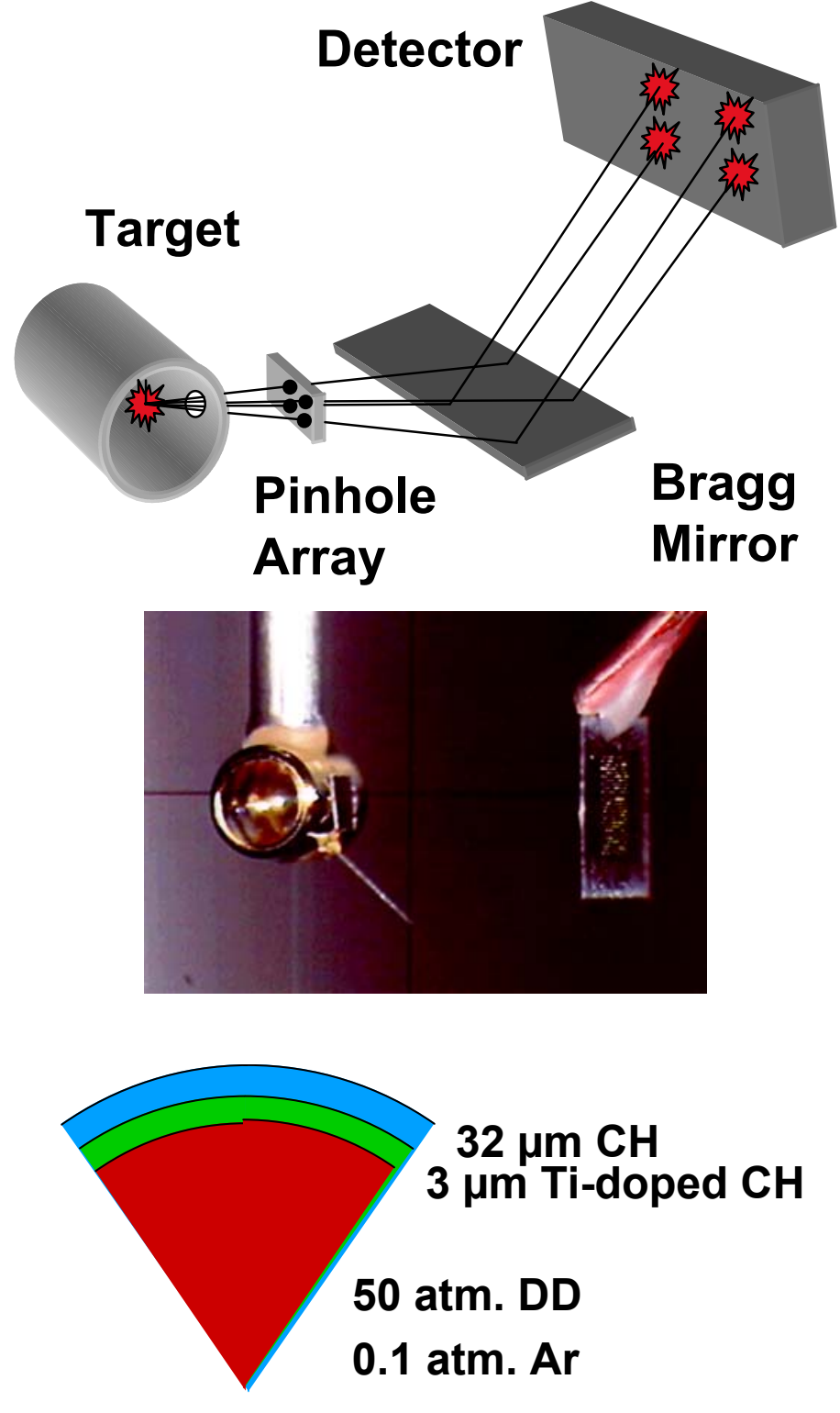


Temperature maps show significant variations depending on drive symmetry
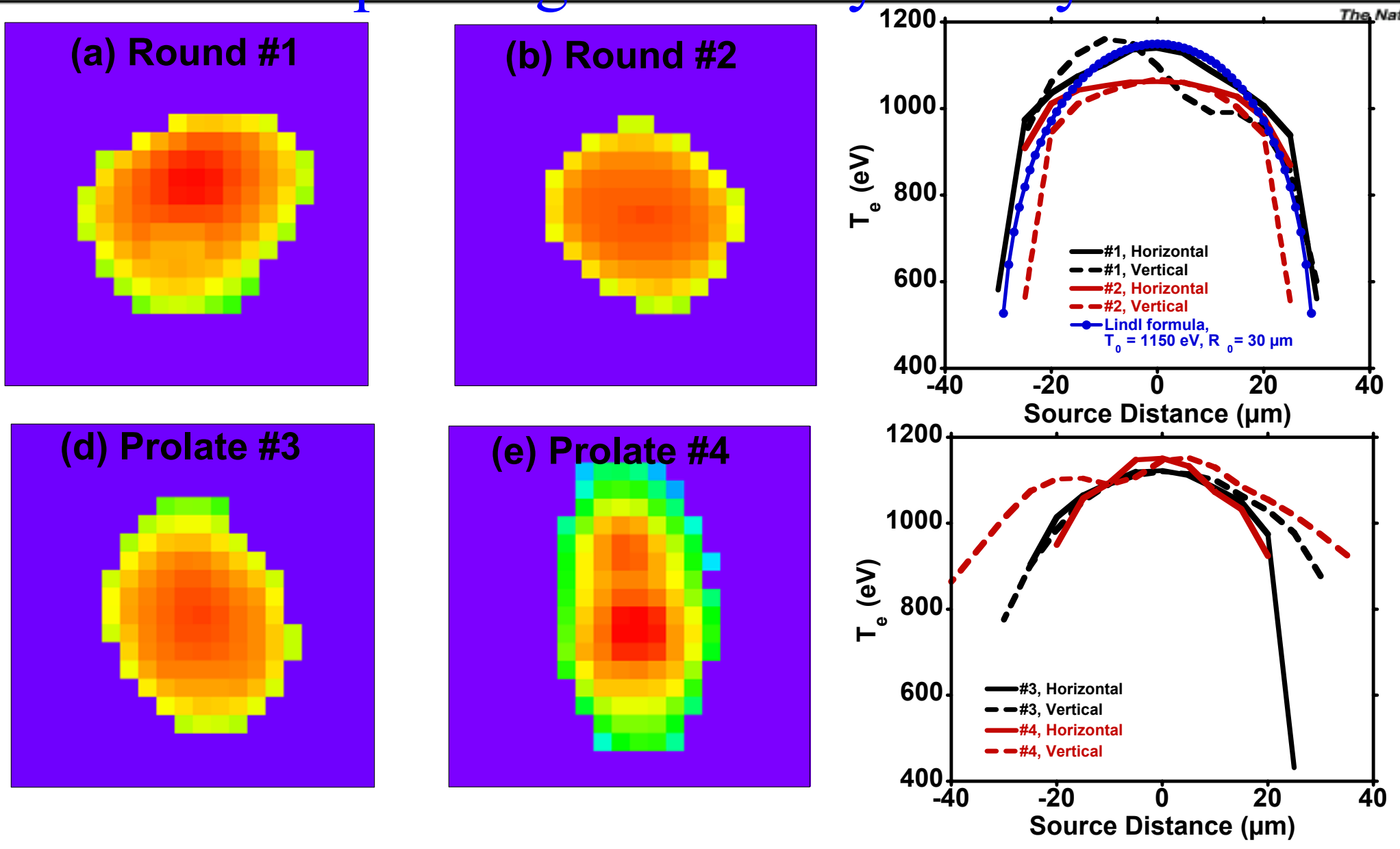

- General shape of round cores reasonably consistent with Lindl profile

- Two-lobed temperature profile appears for highly prolate implosions

- Consistent with $\sim 9 \mathrm{keV}$ x-ray images from similar implosions 
Thomson-scattering on $\mathrm{Kr}$ gas bag measures a temperature of $3.2 \mathrm{keV}$ while heater beams are on.

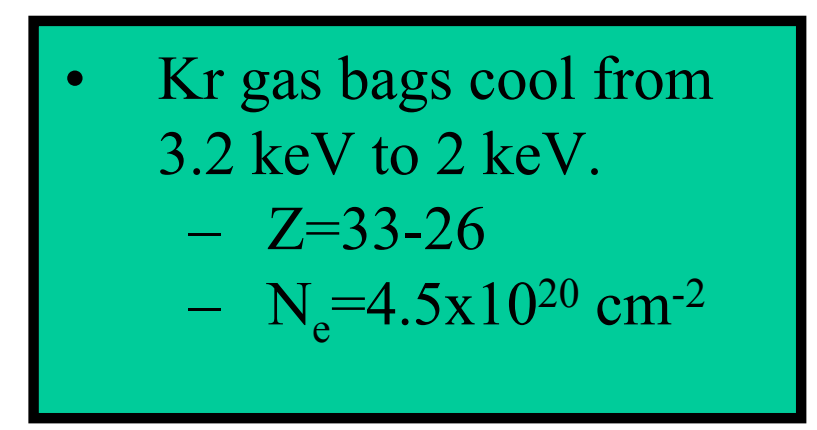

- 2 shots with $\mathrm{C} 5 \mathrm{H} 12+$ $1 \%$ Ar show $\mathrm{T}_{\mathrm{e}}=1.7 \mathrm{keV}$ late in time.

$-\mathrm{N}_{\mathrm{e}}=6 \times 10^{20} \mathrm{~cm}^{-2}$

- $\mathrm{C} 5 \mathrm{H} 12+3 \% \mathrm{Xe}$ show $\mathrm{T}_{\mathrm{e}}=1.5 \mathrm{keV}$ late in time.

$-\mathrm{N}_{\mathrm{e}}=6 \times 10^{20} \mathrm{~cm}^{-2}$
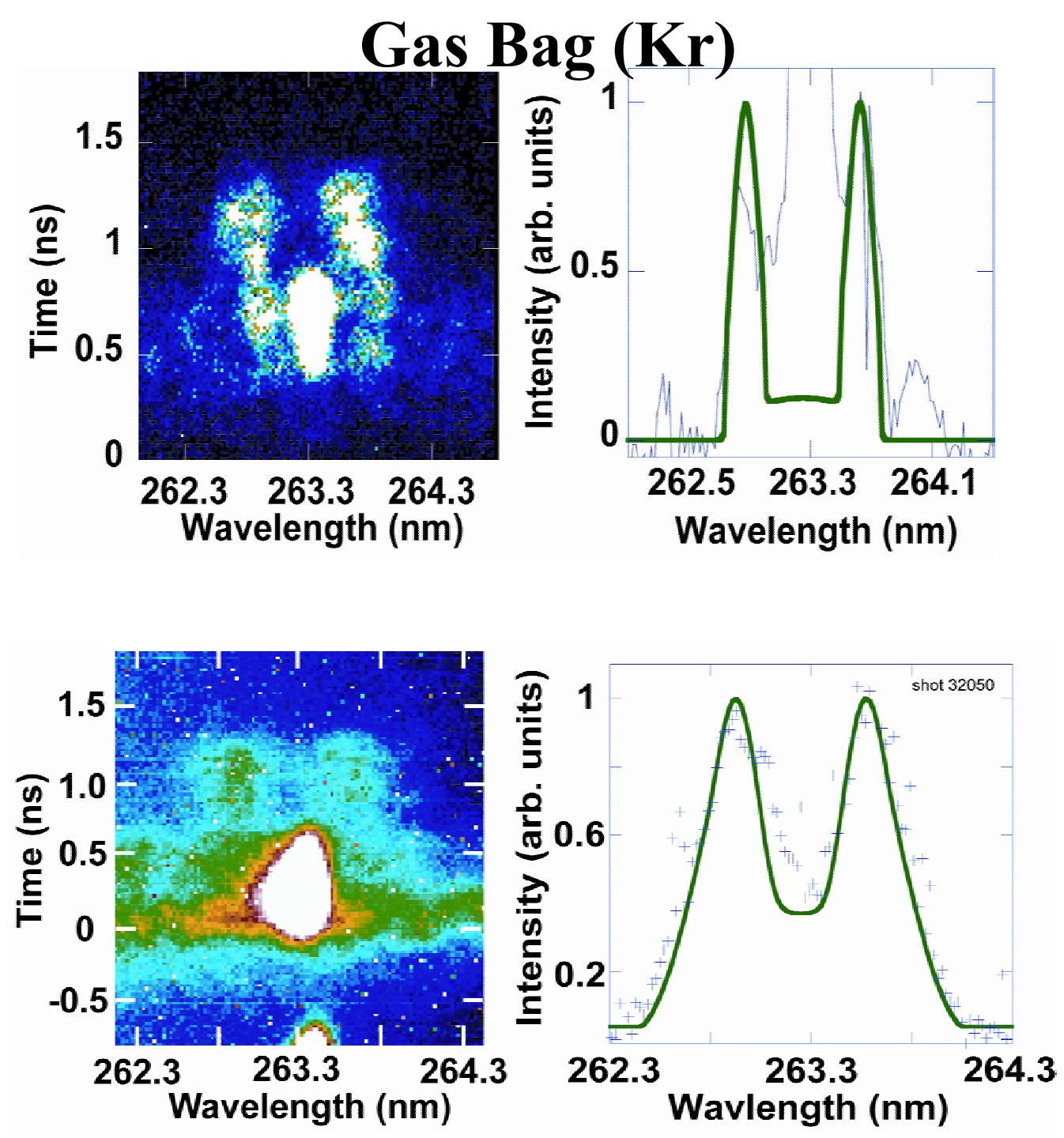
X-ray re-emission images show glint from cone 2, but not from cone 3 .

Experimental image

Simulated image
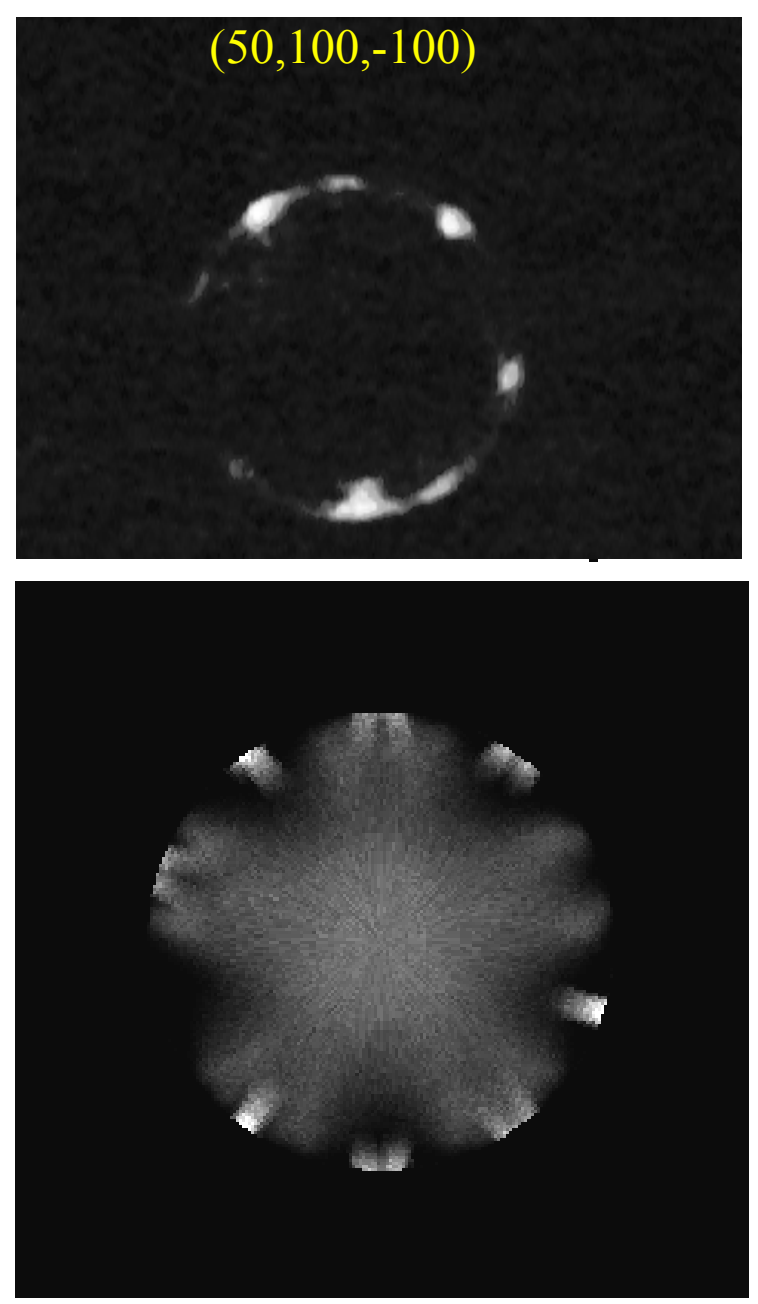


\section{High flux effects on diamond neutron sensor}

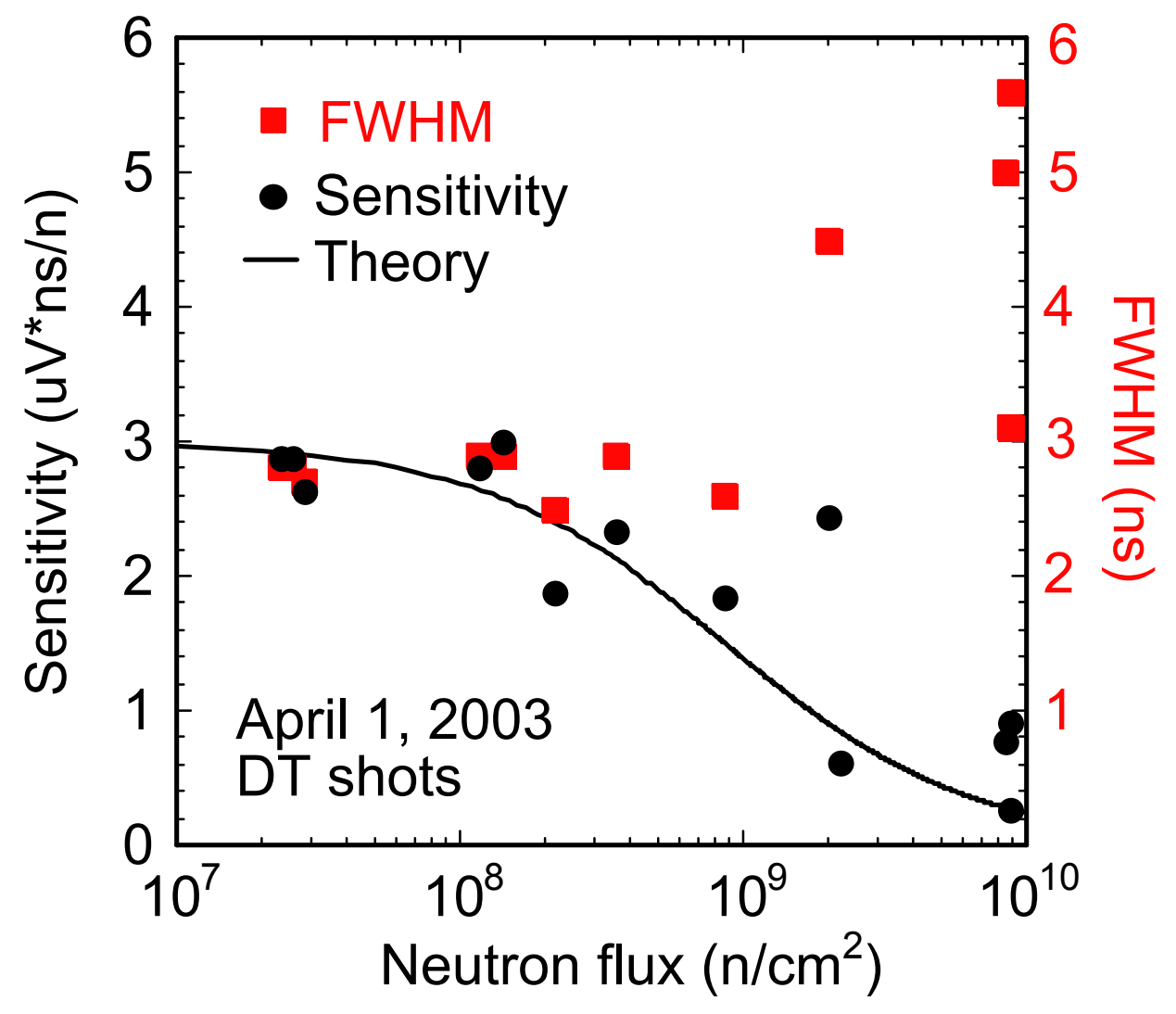

- Diamond detector

- $10 \mathrm{~mm}$ diam, $1 \mathrm{~mm}$ thick

- $1000 \mathrm{~V}$ bias

$-50 \mu \mathrm{CCD}$

- Impedance of transmission line causes saturation at $\mathrm{I}_{\max }=\mathrm{V} / \mathrm{Z}$.

- Theory curve is adapted from x-ray work by Kania et al, Journal of Applied Physics 68, 124 (1990). 
Single line-of-sight backlit pinhole imaging was used

successfully on a driven shock-sphere target

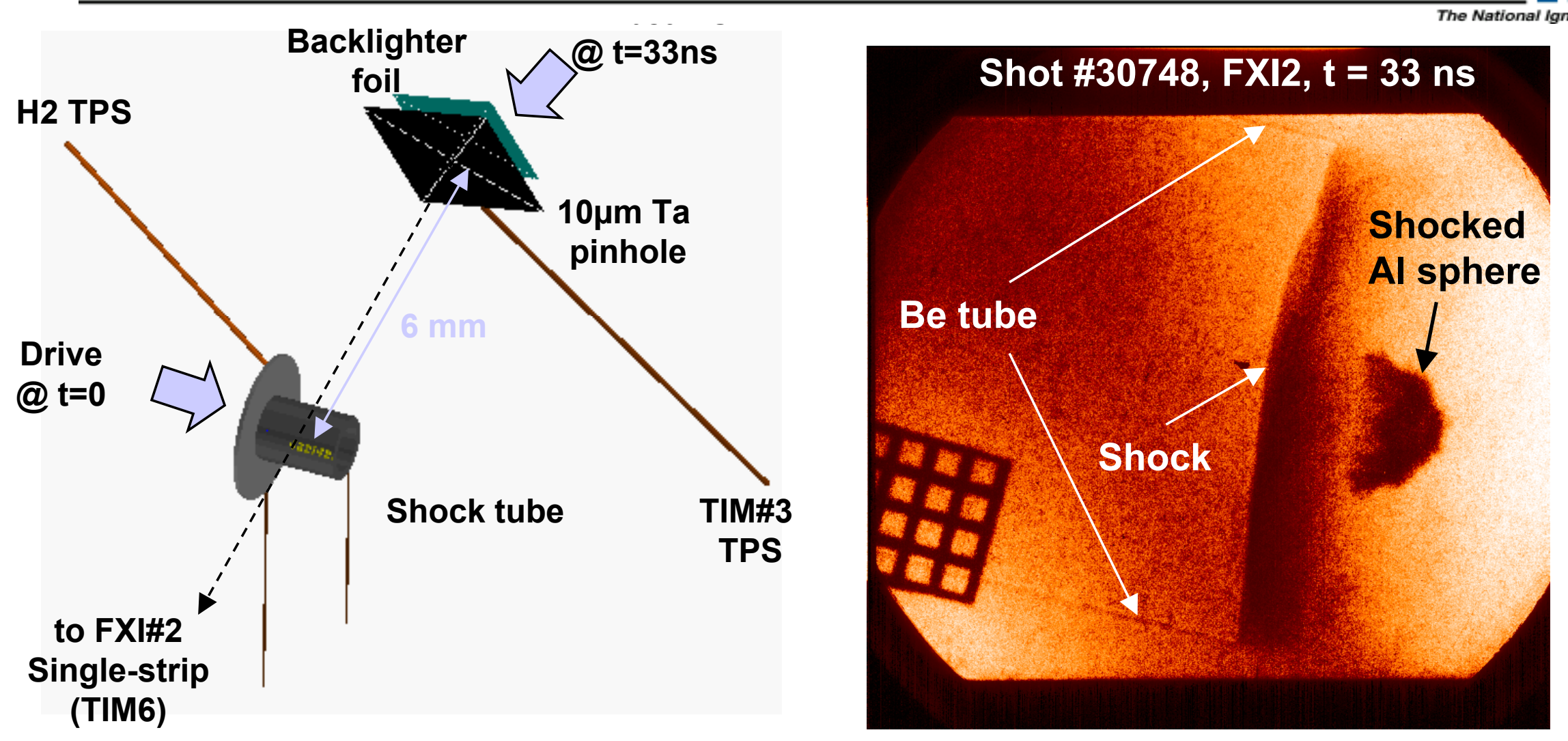

- magnification $=39, \mathrm{FOV}=875 \mu \mathrm{m} \times 1050 \mu \mathrm{m}$

- Shot was compromised by an error in drive energy (70 J/beam vs. 500 requested), resulting in reduced temporal development of interaction. 


\section{Experimental, DAC}
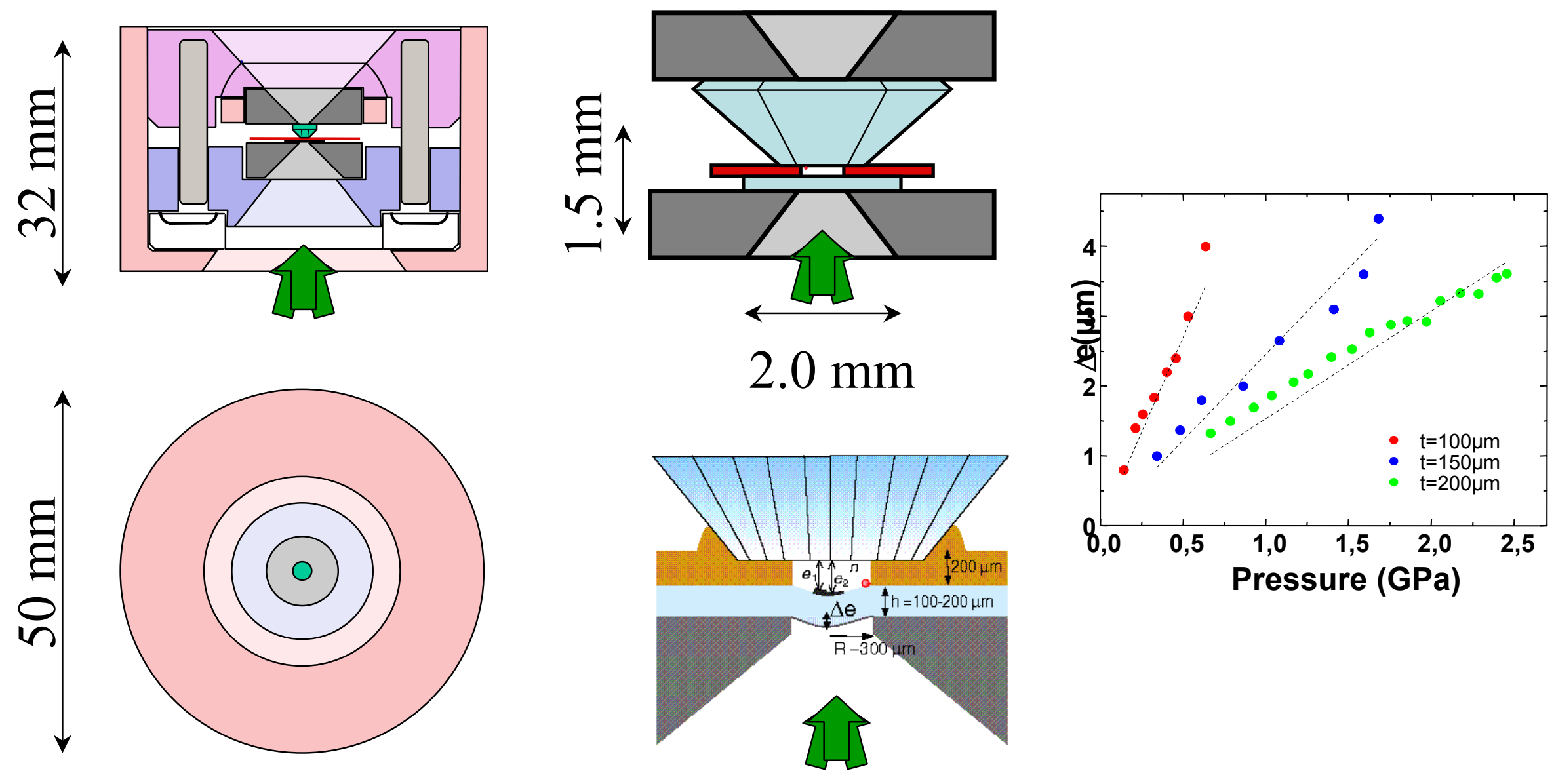